\title{
Article \\ Understanding Balance Control in the Context of Riding a Personal Mobility Device
}

\author{
Donggun Park ${ }^{1}$, Yushin Lee ${ }^{2, *}$ and Myunghwan Yun ${ }^{1}$ (I) \\ 1 Department of Industrial Engineering, Seoul National University, Seoul 08826, Korea; \\ donggun.park@snu.ac.kr (D.P.); mhy@snu.ac.kr (M.Y.) \\ 2 Major in Industrial Data Science \& Engineering, Department of Industrial and Data Engineering, \\ Pukyong National University, Busan 48513, Korea \\ * Correspondence: ysl@pknu.ac.kr
}

check for

updates

Citation: Park, D.; Lee, Y.; Yun, M. Understanding Balance Control in the Context of Riding a Personal Mobility Device. Appl. Sci. 2021, 11, 4173. https://doi.org/10.3390/app11094173

Academic Editor: Alessandro Naddeo

Received: 8 March 2021

Accepted: 30 April 2021

Published: 3 May 2021

Publisher's Note: MDPI stays neutral with regard to jurisdictional claims in published maps and institutional affiliations.

Copyright: (c) 2021 by the authors. Licensee MDPI, Basel, Switzerland. This article is an open access article distributed under the terms and conditions of the Creative Commons Attribution (CC BY) license (https:/ / creativecommons.org/licenses/by/ $4.0 /)$.

\begin{abstract}
This study aimed at investigating the human ability to shift weight and maintain balance when driving a self-balancing personal mobility device (SPMD). In the experiment, participants performed a weight-shifting task, which is moving the center of pressure (COP) toward 15 targets comprising three distances and five directions. They were also given a maintaining balance task, which is holding the COP as close as possible to the same targets. The results showed that during the weight-shifting task, the target distance significantly increased the movement time and decreased the movement fluency and accuracy. In the balance control task, while the target distance significantly affected the postural stability, the target direction had no major effect, although there were interaction effects with the direction on the postural sway along the medial-lateral direction. It is expected that this study can help in understanding the balance control of humans and design safer SPMDs.
\end{abstract}

Keywords: weight-shift; balance control; personal mobility device; human ability; whole-body movement; center of pressure

\section{Introduction}

A personal mobility device (PMD) is a compact, motorized vehicle that has no internal combustion engine and uses electricity as its primary and secondary power sources for transporting an individual. It is also known as personal mobility, personal mobility vehicle, and smart mobility depending on the country, media, and researcher. The PMD originated in the late 1990s, initially dominated by electric scooters/mopeds and electric bicycles, with the addition of the Segway PT [1]. It has some unique characteristics compared to other types of vehicles. It is eco-friendly because it uses electricity as a power source and it does not emit pollutants when driving on the road. If PMDs can replace existing vehicles for some short-distance driving or improve accessibility to public transport, they can greatly reduce congestion and pollutant emissions [2,3]. Additionally, their portability is superior because of their small size and light weight compared to other types of vehicles. The majority of PMDs are designed to be small or foldable, making them convenient to carry in other vehicles or in public transport (without the concern of parking shortages) and easy to store. Owing to these features, the PMD is emerging as an alternative means of transportation for short distances in the urban environment and is gaining the spotlight as the first/last-mile connection with other means of transportation [4-6].

Among the various types of PMDs, self-balancing PMDs (SPMDs), which are controlled by weight shifting, are continuously being developed and attracting increasing attention. Consequently, they have become a representative type of the PMD. There are many types of SPMDs such as Segway PT, Segway mini, hoverboards, electric unicycles, and electric one-wheel skateboards. By leaning anteriorly or posteriorly, the rider can move the SPMD forward or backward. It is also applied by leaning to the lateral directions when riding the electric one-wheel skateboard. The more the rider tilts their body, the faster the 
vehicle moves. To maintain a constant speed, the rider should maintain their balance with the posture. The method of changing the direction depends on the type of vehicle and the weight-shifting direction. The Segway PT and Segway mini use a handle and a knee control bar to change directions, respectively. The hoverboard is operated similarly to the Segway (but without the handle) using the position and pressure of the rider's foot [7]. The electric unicycle redirects the vehicle by moving the center of gravity left or right as it moves forward. Commonly, they require diagonal weight shifting to change the moving direction of the devices. As an example, the electric unicycle is required to make a right turn by shifting the rider's weights to the right diagonal direction. It is also applied to other devices as well when controlling the moving direction. In summary, weight shifting and maintaining equilibrium are required to move, accelerate, decelerate, and turn the SPMD, and the rider's balance control is very important. As postural control strategies for maintaining balance vary depending on the type of human activity and the environmental condition [8], they are also applied differently depending on the SPMD riding context. Thus, it is necessary to consider the balance control of humans when designing SPMDs.

There are several benefits of considering the human balance control in the design of SPMDs. First, it can be easier for riders to learn how to ride and operate the SPMD. The difficulty of boarding and maneuvering depends on the type of SPMD, and beginners need sufficient practice to gain familiarity with the vehicle and balance control. There are inherent abilities and specific patterns to control human balance, which need to be understood to increase learnability and ease of SPMD operation. Second, the SPMD rider's safety can be improved. The rider controls the direction and speed of the SPMD through weight shifting. Unexpected and rapid weight shifting may be required depending on the riding circumstances such as sudden stops and obstacle avoidance. The balance control and pattern in such conditions can be studied in relation to the design of the SPMD control interface for the safety of riders. As a type of vehicle, the safety of SPMD riders is a very critical aspect. Hence, it is necessary to study human characteristics as in automobile research.

Balance is a generic term used to describe the dynamics of body posture to prevent falling [9]. When a person's center of mass is projected vertically to the ground, the point of contact with the ground is called the center of gravity, and the balance can be stabilized when the point is in the base of support (BOS) [10-12]. Previous studies related to human balance control have evaluated the static and dynamic postural control in humans. In those studies, the center of pressure (COP) measured through a force plate is one of the most widely used parameters for assessing human balance control. The COP is calculated from the ground force measured on a force plate, which is located at the center of the distribution of the total force applied to the support surface, and represents the weighted average of all pressures on the area in contact with the support surface $[13,14]$. The COP can quantitatively evaluate the balance of human static and dynamic postures $[15,16]$. Consequently, it can be used to assess human balance in various fields including human characteristics [17-22], work and environment [23-26], and clinical and rehabilitation [27-29].

Although there are various balance control studies using the COP, the postural controls in the context of SPMD riding need to be further investigated. SPMD riders often have to shift their weights rapidly and accurately to move the vehicle or to avoid an obstacle. They also need to maintain balance with a leaning posture to control the speed of the vehicle. In this regard, there are studies that examined the weight-shifting ability in discrete $\mathrm{COP}$ movements and the postural equilibrium in different leaning postures using the COP. Hernandez et al. $[18,19]$ identified the effects of age on the performance of the COP movement for weight shifting in terms of speed and accuracy with different target distances and compared the anterior and posterior COP movements. They found different control strategies between young and older women in the COP movement speed and the number of submovements. In addition, the movement directions affected the COP movement speed and accuracy. De Vries et al. [30] also investigated the differences between young and older adults by task difficulty in the control of weight shifting in terms of time, 
fluency, and accuracy of the COP movement. In their study, the task difficulty such as target distance and target size affected the weight-shifting performance but there were differences between the two age groups. Duarte and Zatsiorsky [31] investigated the effects of visual information on the maintenance of postural equilibrium in different leaning postures. It was found that balance maintenance was affected by vision and visual feedback in relation to the time when vision was removed, but there were no differences between the vision and visual feedback on the equilibrium maintenance. From the abovementioned studies, it is evident that the target distance and direction have significant effects on the control performance and strategy in the weight shifting and maintenance of postural equilibrium.

Therefore, this study aimed to investigate the balance control of SPMD riders in a simplified and restricted movement simulation. The two objectives of this study were to determine (1) the effects of target distance and direction on the control of weight shifting and (2) the effects of target distance and direction on the balance control. The target distance and direction were specified as visual targets in the limit of stability (LOS) of the subjects using real-time COP feedback. Experiments were designed by the combination of the anterior and lateral COP movements to consider the context of riding the SPMD to move at a standstill and to maintain a constant speed.

\section{Methods}

\subsection{Participants}

Twenty-one young adults (fifteen males and six females) participated in this study. Their mean age, height, and weights were 30.81 years ( $\mathrm{SD}=3.08), 172.43 \mathrm{~cm}(\mathrm{SD}=8.29)$, and $70.56 \mathrm{~kg}(\mathrm{SD}=15.59)$ respectively. After a brief introduction of the experiments, participants self-reported their footedness and any health issues. The participants' footedness data were 17 and 4 for the right and left foot, respectively. All participants were physically and mentally healthy without a history of fracture and any symptom that could affect the mobility of each body limb. They had normal or corrected-to-normal vision. Before the experiment, they provided written informed consent.

\subsection{Apparatus}

A force plate (Bertec 4060, Bertec Corporation, Columbus, OH, USA) was used to record the COP of the participants during the experiment. Forces, moments, and COP positions were collected at a sampling rate of $1000 \mathrm{~Hz}$. A TV screen was located $2 \mathrm{~m}$ away in front of the participants. A customized software was used to display the real-time COP position on the screen as a black dot while participants were performing tasks. The ratio of the COP movements between the screen and force plate was set to 5 .

\subsection{Tasks}

The objectives of the experiment were to determine the weight-shifting ability of SPMD riders in specific COP movement contexts and to identify their abilities of maintaining balance with different leaning postures. The experiment consisted of two sessions which were a weight-shifting task and a balance task.

In the first session, participants performed the weight-shifting task. They had to shift their weights using their whole body while maintaining their feet in contact with the force plate to move the COP from a home target to a goal target as rapidly and accurately as possible in each trial. The home target where the COP movement began was determined by the COP's neutral position of each participant. Three distances and five directions were established to decide the positions of the goal targets. The three target distances were 30, 60, and $90 \mathrm{~mm}$ in terms of COP displacement referred to as distance 1, distance 2, and distance 3 , respectively. The maximum target distance was determined based on the LOS of young adults in the anterior and posterior direction, which was found as $11 \mathrm{~cm}$ in the research by Prado et al. [32]. The five directions were the wind directions (E, NE, N, NW, and W). A goal target was randomly assigned for each trial from 15 possible target positions (Figure 1). Square boxes with a size of $20 \times 20 \mathrm{~mm}$ in terms of COP displacement were 
used to represent both the home and goal targets for the weight-shifting task. They were displayed on the screen at the start of each trial.

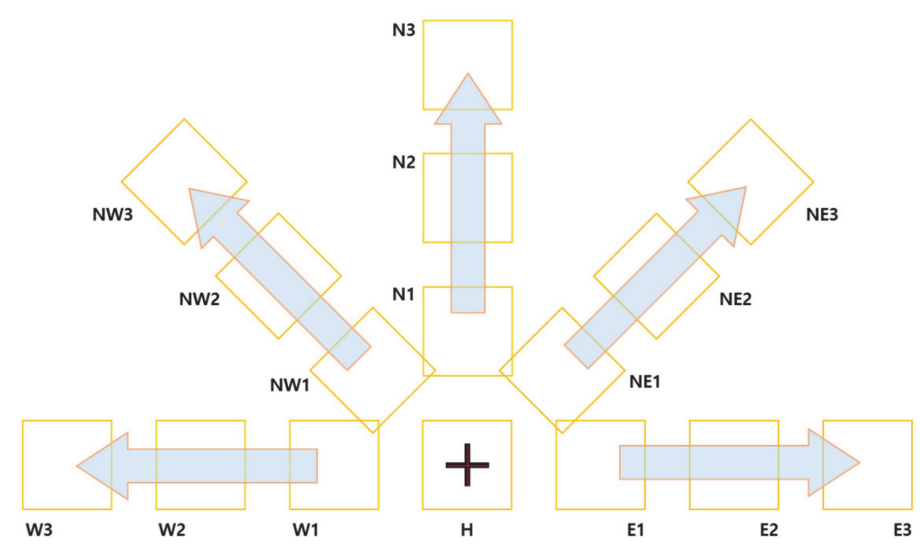

Figure 1. Schematic overview of all possible target positions and movement directions in the weightshifting task.

In the second session, participants performed the balance task. They had to control their balance to hold their COP at the target positions as close as possible while maintaining their feet in contact with the force plate. The target positions were determined as they were in the first session. A target was randomly assigned for each trial from 15 possible target positions (Figure 2). The target position was displayed on the screen at the start of each trial as a red cross $(\times$ mark $)$.

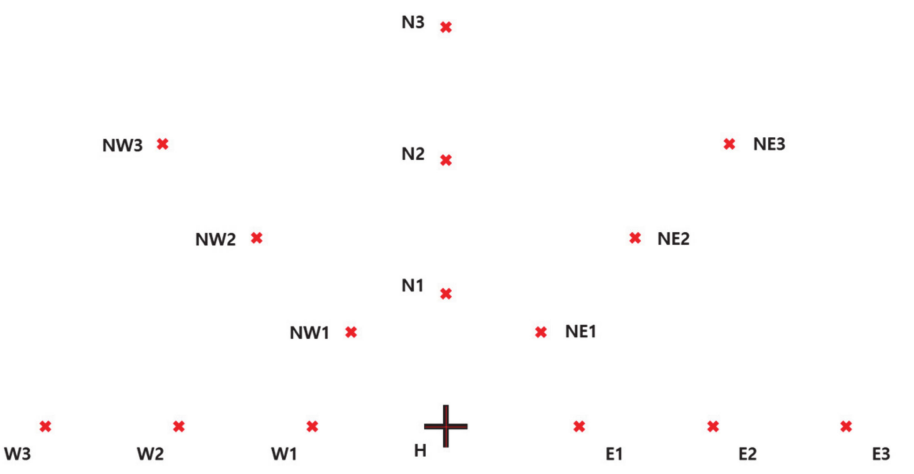

Figure 2. Schematic overview of all possible target positions in the balance task.

\subsection{Procedure}

The participants were instructed to wear comfortable canvas shoes on the day of the experiment. A white paper was taped on the force plate to trace and maintain the foot positions of each participant throughout the sessions. The participants stood on the force plate in a side-by-side stance with their feet spread at shoulder width. Their COPs were recorded for $30 \mathrm{~s}$ while they were standing in a neutral posture as still as possible without COP feedback on the TV screen. The average of the COP positions was used as the COP's neutral position of each participant (i.e., reference point). Before the experiment started, the participants were given enough time for the practice of the weight-shifting and balance tasks repeatedly with real-time COP feedback to become familiarized with the experimental setup and to perform the tasks without the constraints on the ankle or hip postural movement strategy.

In the first session, an auditory signal was used to start each trial in the weight-shifting task. The signal was given to the participants after their COP remained in the home target for more than $1 \mathrm{~s}$. In each trial, they moved the COP to a randomly given goal target as 
quickly and accurately as possible. The trial was completed when the COP remained in the goal target for $0.5 \mathrm{~s}$. After each trial, subjective assessments were conducted.

After the first session, the participants were allowed a 10 min break while sitting on a chair. In the succeeding session, a target position was randomly given to the participants to locate and maintain their COP on the position as still as possible. The participants verbally expressed themselves when they felt stable at that position, and $3 \mathrm{~s}$ of force plate data were collected. After each trial, subjective assessments were performed as they were in the first session. The entire experiment for each participant lasted approximately $45 \mathrm{~min}$.

\subsection{Measures}

Raw COP data from the weight-shifting and balance tasks were processed using custom software written in MATLAB (ver. 8.6.0, The MathWorks, Inc., Natick, MA, USA). A fourth-order zero-lag low-pass Butterworth filter with a $5 \mathrm{~Hz}$ cutoff frequency was used to filter the COP data by referring the previous related studies [30,33,34]. Some of the raw data for one participant were distorted during the recording of the weight-shifting task and discarded before the analysis. Thus, only the data of 20 participants were used in the analysis of the weight-shifting task, while the data of all participants were used in the analysis of the balance task.

\subsubsection{Weight-Shifting Task}

In the weight-shifting task, the COP movement was classified into two phases, namely primary submovement (PSM) and secondary submovement (SSM), to investigate the fluency and accuracy of the movement, respectively (Figure 3). The PSM is defined as the COP movement until the COP reaches a goal target for the first time. The SSM is the COP movement following the PSM until the trial is completed (i.e., when the COP remains in a goal target for $0.5 \mathrm{~s}$ ). Ten outcome measures were derived from the COP movement data.

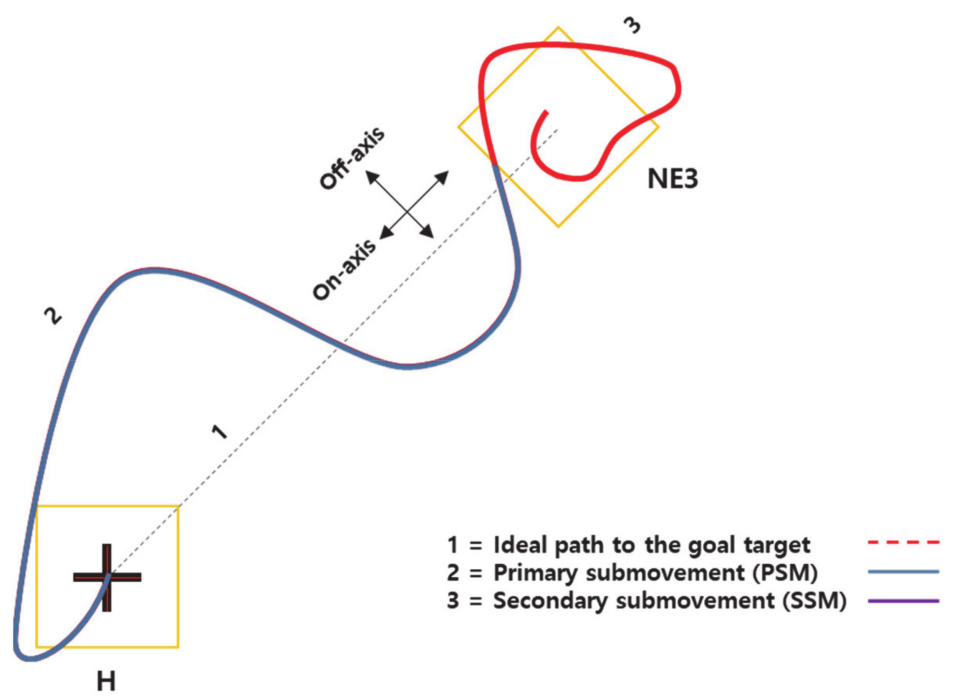

Figure 3. Schematic overview of the COP movement trajectory.

- $\quad$ Time measures

In the perspective of the COP movement time, the time taken to complete a trial is referred to as the movement time (MT). Moreover, the time taken to reach a goal target is called the movement time of the PSM (MT $\mathrm{PMS}_{\mathrm{P}}$ ).

- $\quad$ Fluency measures

In terms of fluency, four outcome measures were derived based on the COP trajectory

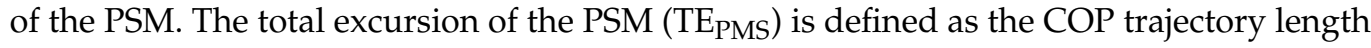
until the COP reaches a goal target. The maximal deviation (MD) indicates the farthest 
distance in the off-axis of the PSM. The directional control (DC), which expresses the degree of COP control of the PSM, is the difference between the on-axis COP movement length and the off-axis COP movement length divided by the on-axis movement length in the PSM expressed as a percentage [35]. The non-minimum phase (NMP) behavior, which explains the COP movement in the direction opposite to the intended direction at the initiation of the weight-shifting trial based on control theory [36], was applied to derive the magnitude of the NMP $\left(\mathrm{d}_{\mathrm{NMP}}\right)$, which is the distance from the initial COP point to the farthest point in the NMP.

- Accuracy measures

Four outcome measures were derived from the SSM in terms of accuracy of the COP movement. The total excursion of the SSM (TESSM) is defined as the COP trajectory length until a trial is completed in the SSM. The dwelling time (DT) is the time taken until a trial is completed in the SSM. The maximum COP excursion (ME) indicates the farthest distance along the on-axis from the target COP point during the COP movement in each trial. The target area (TA) was derived from the $95 \%$ confidence ellipse area of the COP movements in the SSM.

- $\quad$ Subjective measures

The following four items were subjectively evaluated for each trial based on a 5-point Likert scale (Appendix A): perceived performance (PP), ease of task (ET), perceived stability (PS), and physical comfort (PC). A higher value indicates that the participant felt strongly agree to the four question items respectively when shifting the participant's weights to the target COP location.

\subsubsection{Balance Task}

\section{- Time-domain measures}

In the balance task, 11 outcome measures were derived from the COP data to measure postural steadiness. They are commonly used variables and referred from Prieto et al. [34]. Nine measures were derived based on the distance computed from the time series of COP data in both the anterior-posterior (AP) and medial-lateral (ML) directions: mean distance (MDIST), mean distance-AP (MDIST $\mathrm{AP}_{\mathrm{P}}$ ), mean distance-ML (MDIST $\mathrm{ML}_{\mathrm{L}}$ ), root mean square (RMS) distance (RDIST), RMS distance-AP (RDIST ${ }_{\mathrm{AP}}$ ), RMS distance-ML (RDIST $\mathrm{ML}_{\text {), }}$, mean velocity (MVEL), mean velocity-AP (MVEL $\mathrm{AP}_{\mathrm{A}}$ ), and mean velocity-ML (MVEL $\mathrm{ML}_{\mathrm{ML}}$ ). The MDIST indicates the average distance from the mean COP. The RDIST is the RMS distance between the COP time series and mean COP. The MVEL is defined as the average velocity of the COP movement. The variables with the AP and ML notations indicate that they were derived in the AP and ML directions. The MDISTAP and MDISTML represent the average distances in the AP and ML directions, respectively. The remaining two measures were derived based on the area of the COP movement sway: $95 \%$ confidence circle area $\left(\mathrm{AREA}_{\mathrm{CC}}\right)$ and $95 \%$ confidence ellipse area $\left(\mathrm{AREA}_{\mathrm{CE}}\right)$.

- Subjective measures

The four items of subjective assessment used in the weight-shifting task were also evaluated in the balance task (Appendix A). All the variables used in both weight-shifting and balance tasks are presented in Table 1. 
Table 1. Outcome measures derived from the COP data and subjective assessments in the weight-shifting and balance tasks.

\begin{tabular}{|c|c|c|}
\hline Type of Task & Classification & Outcome Measures \\
\hline \multirow{4}{*}{ Weight-shifting } & Time & $\mathrm{MT}, \mathrm{MT}_{\mathrm{PSM}}$ \\
\hline & Fluency & $\mathrm{TE}_{\mathrm{PSM}}, \mathrm{MD}, \mathrm{DC}, \mathrm{d}_{\mathrm{NMP}}$ \\
\hline & Accuracy & TESSM, DT, ME, TA \\
\hline & Subjective assessments & PP, ET, PS, PC \\
\hline \multirow[t]{2}{*}{ Maintaining balance } & Time-domain measures & $\begin{array}{c}\text { MDIST, } \text { MDIST }_{\mathrm{AP}}, \mathrm{MDIST}_{\mathrm{ML}}, \mathrm{RDIST}, \mathrm{RDIST}_{\mathrm{AP}}, \mathrm{RDIST}_{\mathrm{ML}}, \mathrm{MVEL}, \\
\text { MVEL }_{\mathrm{AP}}, \mathrm{MVEL}_{\mathrm{ML}}, \mathrm{AREA}_{\mathrm{CC}}, \mathrm{AREA}_{\mathrm{CE}}\end{array}$ \\
\hline & Subjective assessments & PP, ET, PS, PC \\
\hline
\end{tabular}

\subsection{Analysis}

A two-way repeated-measures analysis of variance (ANOVA) was performed with the distance and direction as the main factors to examine their effects on the weightshifting strategy and postural sway. Post-hoc tests using multiple comparisons with Fisher's least significant difference were conducted when significant main effects and/or interaction effects were found. When a significant interaction was found, the simple effect of the distance and direction was further investigated using a one-way ANOVA for each combination of the three distances and five directions separately. When the assumption of Mauchly's sphericity was not met, the Hyunh-Feldt correction was used to correct the degree of freedom. The level of significance was set as alpha $=0.05$. All statistical analyses were performed using SPSS version 18.0 (Chicago, IL, USA).

\section{Results}

\subsection{Weight-Shifting Task \\ 3.1.1. Time Measures}

The ANOVA results showed that the target distance $(\mathrm{MT}: \mathrm{F}(1.47,27.84)=47.83$, $\left.p<0.001, \eta \mathrm{p} 2=0.72 ; \mathrm{MT}_{\mathrm{PMS}}: \mathrm{F}(2,38)=39.32, p<0.001, \eta \mathrm{p} 2=0.67\right)$, target direction (MT PMS $\left._{\text {: }} \mathrm{F}(4,76)=5.70, p<0.001, \eta \mathrm{p} 2=0.23\right)$, and interaction of the target distance and direction $\left(\mathrm{MT}_{\mathrm{PMS}}: \mathrm{F}(8,152)=2.65, p=0.009, \eta \mathrm{p} 2=0.12\right)$ had significant effects on the time measures. In Table 2, superscripts of the uppercase and lowercase are used to denote the significant difference within one factor the distance or the direction respectively. In the post-hoc tests (Table 2), the MT and $\mathrm{MT}_{\mathrm{PMS}}$ significantly increased with increasing target distance. The $\mathrm{MT}_{\mathrm{PMS}}$ values were relatively larger in the $\mathrm{E}$ and $\mathrm{W}$ directions than in the other directions. Regarding the interaction effects on the $\mathrm{MT}_{\mathrm{PMS}}$, all simple effects in each level of distance and direction showed significant differences (Table 3). In Table 3, superscripts of the uppercase and lowercase are used to denote the significant difference within one factor by the other. The uppercase letters indicate a significant difference between the target distances in the same column. The lowercase letters indicate a significant difference between the target direction in the same row. As an example, the $\mathrm{MT}_{\mathrm{PSM}}$ showed a significant difference between Distance $3\left(1.74^{\mathrm{B}}\right)$ and others $\left(1.28^{\mathrm{A}}\right.$ and $\left.1.10^{\mathrm{A}}\right)$. It also showed significant differences between the direction NE $\left(1.44^{\mathrm{a}}\right), \mathrm{N}\left(1.16^{\mathrm{b}}\right)$, and $\mathrm{W}\left(0.99^{\mathrm{c}}\right)$. The post-hoc tests showed that the $\mathrm{MT}_{\mathrm{PMS}}$ values in the $\mathrm{N}$ direction significantly increased when the target distance increased. In the $\mathrm{E}$ and $\mathrm{NE}$ directions, the $\mathrm{MT}_{\mathrm{PMS}}$ values were significantly small at distance 1 and distance 2 compared to those at distance 3 . There were no significant differences between the values at distance 1 and distance 2 . However, the $\mathrm{MT}_{\mathrm{PMS}}$ values were significantly large at distance 2 and distance 3 compared to those at distance 1 , but there were no significant differences between the values at distance 2 and distance 3 in the $\mathrm{W}$ and NW directions. 
Table 2. Summary of COP outcomes and subjective assessments in the weight-shifting task.

\begin{tabular}{|c|c|c|c|c|c|c|c|c|c|}
\hline \multirow{2}{*}{ DV } & \multicolumn{3}{|c|}{ Goal Target Distance } & \multicolumn{5}{|c|}{ Goal Target Direction } & \multirow{2}{*}{$\begin{array}{l}\text { Interaction } \\
p \text {-Value }\end{array}$} \\
\hline & Distance 1 & Distance 2 & Distance 3 & E & $\mathbf{N}$ & NE & NW & $\mathbf{W}$ & \\
\hline MT & $2.41^{\mathrm{A}}(0.13)$ & $3.10^{\mathrm{B}}(0.09)$ & $3.61^{\mathrm{B}}(0.13)$ & $2.99(0.11)$ & $3.00(0.17)$ & $3.10(0.12)$ & $3.12(0.15)$ & $2.98(0.12)$ & 0.520 \\
\hline $\mathrm{MT}_{\mathrm{PSM}}$ & $1.18^{\mathrm{A}}(0.06)$ & $1.55^{\mathrm{B}}(0.08)$ & $1.95^{\mathrm{C}}(0.11)$ & $1.38^{\mathrm{b}}(0.07)$ & $1.69^{\mathrm{a}}(0.10)$ & $1.71^{\mathrm{a}}(0.13)$ & $1.66^{\mathrm{a}}(0.09)$ & $1.36^{\mathrm{b}}(0.09)$ & 0.009 \\
\hline TEPSM & $6.00^{\mathrm{A}}(0.31)$ & $10.92^{\mathrm{B}}(0.48)$ & $16.66^{\mathrm{C}}(0.68)$ & $10.96^{\mathrm{c}}(0.54)$ & $9.46^{\mathrm{d}}(0.53)$ & $12.43^{\mathrm{a}}(0.64)$ & $\begin{array}{c}12.07^{\mathrm{ab}} \\
(0.55)\end{array}$ & $\begin{array}{c}11.04^{\mathrm{bc}} \\
(0.56)\end{array}$ & 0.501 \\
\hline MD & $0.99^{\mathrm{A}}(0.07)$ & $1.32^{\mathrm{B}}(0.05)$ & $1.72^{\mathrm{C}}(0.06)$ & $1.05^{\mathrm{b}}(0.06)$ & $0.86^{\mathrm{c}}(0.07)$ & $1.92^{\mathrm{a}}(0.12)$ & $1.85^{\mathrm{a}}(0.13)$ & $1.04^{\mathrm{bc}}(0.07)$ & 0.002 \\
\hline DC & $68.82(2.13)$ & 72.37 (1.47) & $72.71(1.42)$ & $81.23^{\mathrm{a}}(1.83)$ & $78.88^{\mathrm{a}}(1.15)$ & $56.18^{\mathrm{b}}(2.83)$ & $57.78^{\mathrm{b}}(3.55)$ & $82.43^{\mathrm{a}}(1.75)$ & 0.544 \\
\hline $\mathrm{d}_{\mathrm{NMP}}$ & $1.35^{\mathrm{A}}(0.12)$ & $1.91^{\mathrm{B}}(0.19)$ & $2.42^{\mathrm{C}}(0.20)$ & $2.39^{\mathrm{a}}(0.27)$ & $1.28^{\mathrm{c}}(0.14)$ & $1.74^{\mathrm{b}}(0.18)$ & $1.80^{\mathrm{b}}(0.13)$ & $2.26^{\mathrm{a}}(0.18)$ & 0.035 \\
\hline $\mathrm{TE}_{\mathrm{SSM}}$ & $5.53^{\mathrm{A}}(0.56)$ & $6.85^{\mathrm{B}}(0.63)$ & $7.92^{\mathrm{B}}(0.99)$ & $7.65^{\mathrm{a}}(0.87)$ & $4.89^{\mathrm{b}}(0.60)$ & $6.67^{\mathrm{a}}(0.92)$ & $6.84^{\mathrm{a}}(0.86)$ & $7.78^{\mathrm{a}}(0.92)$ & 0.351 \\
\hline DT & $1.23^{\mathrm{A}}(0.10)$ & $1.54^{\mathrm{B}}(0.09)$ & $1.66^{\mathrm{B}}(0.15)$ & $1.61(0.14)$ & $1.30(0.16)$ & $1.39(0.14)$ & $1.46(0.14)$ & $1.62(0.13)$ & 0.664 \\
\hline $\mathrm{ME}$ & $1.26(0.14)$ & $0.92(0.13)$ & $1.13(0.14)$ & $1.16^{\mathrm{a}}(0.16)$ & $0.47^{\mathrm{b}}(0.08)$ & $1.10^{a}(0.18)$ & $1.24^{\mathrm{a}}(0.16)$ & $1.54^{\mathrm{a}}(0.22)$ & 0.191 \\
\hline TA & $4.78(0.75)$ & $6.09(0.80)$ & $7.16(1.11)$ & $6.58^{\mathrm{a}}(0.93)$ & $2.76^{\mathrm{b}}(0.42)$ & $6.99^{\mathrm{a}}(1.39)$ & $7.18^{\mathrm{a}}(1.18)$ & $6.55^{\mathrm{a}}(1.12)$ & 0.148 \\
\hline PP & $3.60^{\mathrm{A}}(0.15)$ & $3.48^{\mathrm{AB}}(0.14)$ & $3.24^{\mathrm{B}}(0.20)$ & $3.33(0.19)$ & $3.43(0.17)$ & $3.43(0.17)$ & $3.47(0.17)$ & $3.53(0.19)$ & 0.015 \\
\hline ET & $3.76^{\mathrm{A}}(0.16)$ & $3.39^{\mathrm{B}}(0.15)$ & $2.96^{\mathrm{C}}(0.17)$ & $3.45^{\mathrm{ab}}(0.19)$ & $3.20^{\mathrm{b}}(0.19)$ & $3.28^{\mathrm{b}}(0.16)$ & $3.20^{\mathrm{b}}(0.17)$ & $3.72^{\mathrm{a}}(0.13)$ & 0.000 \\
\hline PS & $4.49^{\mathrm{A}}(0.09)$ & $3.97^{\mathrm{B}}(0.13)$ & $3.37^{C}(0.16)$ & $4.17^{\mathrm{a}}(0.12)$ & $3.47^{\mathrm{c}}(0.17)$ & $3.87^{\mathrm{b}}(0.15)$ & $3.98^{\mathrm{ab}}(0.12)$ & $4.23^{\mathrm{a}}(0.11)$ & 0.000 \\
\hline PC & $3.67^{\mathrm{A}}(0.13)$ & $3.24^{\mathrm{B}}(0.14)$ & $2.59^{C}(0.13)$ & $3.55^{\mathrm{a}}(0.10)$ & $2.92^{\mathrm{b}}(0.17)$ & $2.98^{\mathrm{b}}(0.12)$ & $2.92^{\mathrm{b}}(0.15)$ & $3.47^{\mathrm{a}}(0.13)$ & 0.000 \\
\hline
\end{tabular}

Note: Values represent mean (standard error). Superscript denotes significant differences by different letters from indicated main effect condition $(p<0.05)$. Uppercase letters are used to indicate the significant difference by target distances 1, 2, and 3. Lowercase letters are used to indicate the significant difference by target directions $\mathrm{E}, \mathrm{N}, \mathrm{NE}, \mathrm{NW}$, and $\mathrm{W}$.

Table 3. Results of ANOVA for simple main effects in the weight-shifting tasks.

\begin{tabular}{|c|c|c|c|c|c|c|}
\hline \multirow{2}{*}{ DV } & \multirow{2}{*}{ Target Distance } & \multicolumn{5}{|c|}{ Target Direction } \\
\hline & & $\mathbf{E}$ & $\mathbf{N}$ & NE & NW & $\mathbf{W}$ \\
\hline \multirow{3}{*}{$\mathrm{MT}_{\mathrm{PSM}}$} & Distance 1 & $1.10^{\mathrm{Abc}}(0.07)$ & $1.16^{\mathrm{Ab}}(0.07)$ & $1.44^{\mathrm{Aa}}(0.14)$ & $1.21^{\mathrm{Aab}}(0.11)$ & $0.99^{\mathrm{Ac}}(0.06)$ \\
\hline & Distance 2 & $1.28^{\mathrm{Ab}}(0.09)$ & $1.68^{\mathrm{Ba}}(0.11)$ & $1.52^{\mathrm{Aab}}(0.13)$ & $1.74^{\mathrm{Ba}}(0.13)$ & $1.55^{\mathrm{Ba}}(0.11)$ \\
\hline & Distance 3 & $1.74^{\mathrm{Bbc}}(0.16)$ & $2.24^{\mathrm{Ca}}(0.20)$ & $2.19^{\mathrm{Ba}}(0.20)$ & $2.04^{\mathrm{Bab}}(0.14)$ & $1.54^{\mathrm{Bc}}(0.15)$ \\
\hline \multirow{3}{*}{ MD } & Distance 1 & $0.75^{\mathrm{Ab}}(0.08)$ & $0.64^{\mathrm{Ab}}(0.08)$ & $1.45^{\mathrm{Aa}}(0.17)$ & $1.34^{\mathrm{Aa}}(0.13)$ & $0.77^{\mathrm{Ab}}(0.09)$ \\
\hline & Distance 2 & $1.10^{\mathrm{Bb}}(0.06)$ & $0.97^{\mathrm{Bb}}(0.12)$ & $1.61^{\mathrm{Aa}}(0.14)$ & $1.75^{\mathrm{Ba}}(0.18)$ & $1.18^{\mathrm{Bb}}(0.13)$ \\
\hline & Distance 3 & $1.31^{\mathrm{Bb}}(0.12)$ & $0.95^{\mathrm{Bc}}(0.11)$ & $2.72^{\mathrm{Ba}}(0.24)$ & $2.47^{\mathrm{Ca}}(0.21)$ & $1.17^{\mathrm{Bbc}}(0.14)$ \\
\hline \multirow{3}{*}{$\mathrm{d}_{\mathrm{NMP}}$} & Distance 1 & $1.49^{\mathrm{Aa}}(0.15)$ & $0.89^{\mathrm{Ab}}(0.11)$ & $1.38^{\mathrm{Aa}}(0.21)$ & $1.31^{\mathrm{Aa}}(0.12)$ & $1.68^{\mathrm{Aa}}(0.23)$ \\
\hline & Distance 2 & $2.57^{\mathrm{Ba}}(0.35)$ & $1.41^{\mathrm{Bc}}(0.21)$ & $1.76^{\mathrm{Bbc}}(0.16)$ & $1.81^{\mathrm{Bbc}}(0.17)$ & $1.97^{\mathrm{Ab}}(0.23)$ \\
\hline & Distance 3 & $3.10^{\mathrm{Ba}}(0.44)$ & $1.53^{\mathrm{Bc}}(0.17)$ & $2.07^{\mathrm{Bbc}}(0.27)$ & $2.28^{\mathrm{Bb}}(0.24)$ & $3.12^{\mathrm{Ba}}(0.28)$ \\
\hline \multirow{3}{*}{ PP } & Distance 1 & $3.30(0.22)$ & $3.90^{\mathrm{A}}(0.20)$ & $3.55^{\mathrm{AB}}(0.24)$ & $3.60(0.26)$ & $3.65(0.24)$ \\
\hline & Distance 2 & $3.25(0.24)$ & $3.55^{\mathrm{A}}(0.20)$ & $3.70^{\mathrm{A}}(0.21)$ & $3.40(0.18)$ & $3.50(0.19)$ \\
\hline & Distance 3 & $3.45^{\mathrm{a}}(0.21)$ & $2.85^{\mathrm{Bb}}(0.29)$ & $3.05^{\mathrm{Bb}}(0.22)$ & $3.40^{\mathrm{a}}(0.22)$ & $3.45^{\mathrm{a}}(0.24)$ \\
\hline \multirow{3}{*}{ ET } & Distance 1 & $3.65(0.21)$ & $3.90^{\mathrm{A}}(0.22)$ & $3.70^{\mathrm{A}}(0.21)$ & $3.55^{\mathrm{A}}(0.22)$ & $4.00(0.21)$ \\
\hline & Distance 2 & $3.40(0.20)$ & $3.35^{\mathrm{A}}(0.23)$ & $3.45^{\mathrm{A}}(0.21)$ & $3.15^{\mathrm{B}}(0.20)$ & $3.60(0.18)$ \\
\hline & Distance 3 & $3.30^{\mathrm{ab}}(0.24)$ & $2.35^{\mathrm{Bd}}(0.23)$ & $2.70^{\mathrm{Bcd}}(0.21)$ & $2.90^{\mathrm{Bbc}}(0.20)$ & $3.55^{\mathrm{a}}(0.20)$ \\
\hline \multirow{3}{*}{ PS } & Distance 1 & $4.70^{\mathrm{A}}(0.11)$ & $4.35^{\mathrm{A}}(0.17)$ & $4.35^{\mathrm{A}}(0.15)$ & $4.40^{\mathrm{A}}(0.13)$ & $4.65^{\mathrm{A}}(0.13)$ \\
\hline & Distance 2 & $4.00^{\mathrm{B}}(0.18)$ & $3.75^{\mathrm{B}}(0.20)$ & $3.85^{\mathrm{B}}(0.18)$ & $4.05^{\mathrm{B}}(0.15)$ & $4.20^{\mathrm{B}}(0.16)$ \\
\hline & Distance 3 & $3.80^{\mathrm{Ba}}(0.19)$ & $2.30^{\mathrm{Cb}}(0.24)$ & $3.40^{\mathrm{Ca}}(0.25)$ & $3.50^{\mathrm{Ca}}(0.20)$ & $3.85^{\mathrm{Ca}}(0.17)$ \\
\hline \multirow{3}{*}{ PC } & Distance 1 & $4.15^{\mathrm{Aa}}(0.15)$ & $3.85^{\mathrm{Aa}}(0.20)$ & $3.30^{\mathrm{Ab}}(0.21)$ & $3.30^{\mathrm{Ab}}(0.19)$ & $3.75^{\mathrm{a}}(0.19)$ \\
\hline & Distance 2 & $3.70^{\mathrm{Ba}}(0.15)$ & $3.05^{\mathrm{Bbc}}(0.22)$ & $3.15^{\mathrm{Abc}}(0.20)$ & $2.90^{\mathrm{Bc}}(0.22)$ & $3.40^{\mathrm{ab}}(0.18)$ \\
\hline & Distance 3 & $2.80^{\mathrm{Cb}}(0.17)$ & $1.85^{\mathrm{Cc}}(0.21)$ & $2.50^{\mathrm{Bb}}(0.17)$ & $2.55^{\mathrm{Bb}}(0.17)$ & $3.25^{\mathrm{a}}(0.19)$ \\
\hline
\end{tabular}

Note: Values represent mean (standard error). Superscript with uppercase letters denotes significant differences from the target distance effect condition $(p<0.05)$ within each target direction. Superscript with lowercase letters denotes significant differences from the target direction effect condition $(p<0.05)$ within each target distance.

\subsubsection{Fluency Measures}

The ANOVA results showed that the target distance (TE ${ }_{\text {PMS }}: \mathrm{F}(1.61,30.60)=212.62$, $p<0.001, \eta p 2=0.92 ; \mathrm{MD}: \mathrm{F}(2,38)=65.40, p<0.001, \eta \mathrm{p} 2=0.78 ; \mathrm{d}_{\mathrm{NMP}}: \mathrm{F}(2,38)=38.43$, $p<0.001, \eta \mathrm{p} 2=0.67)$, target direction $\left(\mathrm{TE}_{\mathrm{PMS}}: \mathrm{F}(4,76)=7.37, p<0.001, \eta \mathrm{p} 2=0.28\right.$; $\mathrm{MD}$ : $\mathrm{F}(4,76)=32.05, p<0.001, \eta \mathrm{p} 2=0.63 ; \mathrm{DC}: \mathrm{F}(4,76)=33.21, p<0.001, \eta \mathrm{p} 2=0.64 \mathrm{~d}_{\mathrm{NMP}}: \mathrm{F}(4$, $76)=14.86, p<0.001, \eta p 2=0.44)$, and interaction of the target distance and direction (MD: $\left.\mathrm{F}(5.19,98.68)=4.01, p=0.002, \eta p 2=0.17 ; \mathrm{d}_{\mathrm{NMP}}: \mathrm{F}(5.83,110.79)=2.37, p=0.035, \eta p 2=0.11\right)$ had significant effects on the fluency of COP movement. Regarding the distance, the 
post-hoc tests revealed that a farther target distance increased the (a) total length of the PSM movement, (b) maximal deviation along the off-axis, and (c) NMP distance (Table 2). In the post-hoc results of the target direction, the PSMs in the diagonal directions (NE and NW) showed relatively longer and larger trajectories with low directional control. In contrast, those in the $\mathrm{E}$ and $\mathrm{W}$ directions were similar but show different $\mathrm{COP}$ movements with shorter trajectories, better directional control, and longer NMP distance (Table 2). Regarding the interaction effects on the MD and $\mathrm{d}_{\mathrm{NMP}}$, all simple effects in each level of distance and direction showed significant differences (Table 3). The MDs between distance 2 and distance 3 in the N, E, and W directions showed no statistically significant differences, while the MDs between distance 2 and distance 3 in the NE and NW directions showed significant differences. The MDs in the NE and NW directions were significantly large at each distance compared to those in the other directions. The $d_{N M P}$ values in the $\mathrm{W}$ direction were significantly small at distance 1 and distance 2 compared to those at distance 3 , but there were no significant differences between the values at distance 1 and distance 2 . In all other directions, there were significant differences in the $\mathrm{d}_{\mathrm{NMP}}$ values between distance 1 and distance 2, while there were none between distance 2 and distance 3 . Additionally, the $\mathrm{d}_{\mathrm{NMP}}$ values in the $\mathrm{N}$ direction at each distance were significantly smaller than those in the other directions.

\subsubsection{Accuracy Measures}

The ANOVA results showed that the target distance $\left(\mathrm{TE}_{\mathrm{SSM}}: \mathrm{F}(1.51,28.68)=5.25\right.$, $p=0.018, \eta \mathrm{p} 2=0.22 ; \mathrm{DT}: \mathrm{F}(1.67,31.73)=6.35, p=0.007, \eta \mathrm{p} 2=0.25)$ and the target direction (TESSM: $\mathrm{F}(4,76)=3.25, p=0.016, \eta p 2=0.15 ; \mathrm{ME}: \mathrm{F}(2.95,55.95)=7.40, p<0.001, \eta p 2=0.28$; TA: $\mathrm{F}(4,76)=4.52, p=0.002, \eta \mathrm{p} 2=0.19)$ had significant effects on the accuracy of the weight-shifting task. There was no significant interaction effect of the target distance and direction. In the post-hoc results of the main effects (Table 2), the TESSM and DT between distance 1 and distance 3 and between distance 1 and distance 2 had significant differences, while there were no significant differences between those of distance 2 and distance 3 . Regarding the direction, three outcomes showed the same patterns in the post-hoc results, where only the values in the $\mathrm{N}$ direction were significantly different from those in all other directions. The values in the remaining directions (E, NE, NW, and W) were not significantly different from each other in terms of the $\mathrm{TE}_{\mathrm{SSM}}, \mathrm{ME}$, and TA.

\subsubsection{Subjective Measures}

The ANOVA results showed that the target distance (PP: $\mathrm{F}(2,38)=4.32, p=0.020$, $\eta \mathrm{p} 2=0.19$; $\mathrm{ET}: \mathrm{F}(2,38)=17.47, p<0.001, \eta \mathrm{p} 2=0.48 ; \mathrm{PS}: \mathrm{F}(1.45,27.50)=43.29, p<0.001$, $\eta p 2=0.70 ; \mathrm{PC}: \mathrm{F}(2,38)=25.96, p<0.001, \eta \mathrm{p} 2=0.58)$, target direction $(\mathrm{ET}: \mathrm{F}(4,76)=4.34$, $p=0.003, \eta p 2=0.19$; PS: $\mathrm{F}(3.03,57.54)=10.83, p<0.001, \eta p 2=0.36$; PC: $\mathrm{F}(4,76)=9.58$, $p<0.001, \eta \mathrm{p} 2=0.34)$, and interaction of the target distance and direction $(\mathrm{PP}: \mathrm{F}(8,152)=2.48$, $p=0.015, \eta \mathrm{p} 2=0.12 ; \mathrm{ET}: \mathrm{F}(8,152)=3.76, p<0.001, \eta \mathrm{p} 2=0.17$; PS: $\mathrm{F}(8,152)=5.88, p<0.001$, $\eta \mathrm{p} 2=0.24 ; \mathrm{PC}: \mathrm{F}(8,152)=5.58, p<0.001, \eta \mathrm{p} 2=0.23)$ had significant effects on the subjective measures of the weight-shifting task. In the post-hoc tests on the main effects, the subjective ratings decreased when the goal target was located farther and increased when the target was located in the $\mathrm{E}$ and $\mathrm{W}$ directions compared to those in the other directions (Table 2). In the post-hoc tests on simple effects (Table 3 ), the PP values were significantly different by distance in the $\mathrm{N}$ and $\mathrm{NE}$ directions. By direction, the PP values were significantly different at distance 3 but not at distance 1 and distance 2 . At distance 3 , the $\mathrm{N}$ and NE direction PP values were significantly small compared to those in the other directions. The ET values were significantly different by distance in the N, NE, and NW directions. By direction, they were significantly different at distance 3 but not at distance 1 and distance 2 . At distance 3, the ET values decreased from the left and right directions (W and E) to the forward directions (NW, NE, and N). The PS values were significantly different by distance in all directions; however, by direction, they were only significantly different at distance 3. At distance 3 , the PS values were significantly small in the $\mathrm{N}$ direction compared to 
those in all other directions. The PC values were significantly different by distance in all directions except for those in the $\mathrm{W}$ direction. In the NE direction, the PC values between distance 1 and distance 2 were not significantly different, but they were significantly larger than those at distance 3. In the NW direction, the PC values were not significantly different at distance 2 and distance 3 but they were significantly smaller than those at distance 1 . A comparison of the values in the directions at each distance showed that the PC in the E and $\mathrm{W}$ directions were significantly larger than those in the other directions.

\subsection{Balance Task}

\subsubsection{Time-Domain Measures}

The ANOVA results showed that the target distance (MDIST: $\mathrm{F}(2,40)=10.81, p<0.001$, $\eta \mathrm{p} 2=0.35 ; \mathrm{MDIST}_{\mathrm{AP}}: \mathrm{F}(2,40)=4.87, p=0.013, \eta \mathrm{p} 2=0.20 ; \operatorname{MDIST}_{\mathrm{ML}}: \mathrm{F}(2,40)=19.20$, $p<0.001, \eta \mathrm{p} 2=0.49$; RDIST: $\mathrm{F}(1.66,33.12)=10.29, p=0.001, \eta \mathrm{p} 2=0.34 ; \mathrm{RDIST}_{\mathrm{AP}}$ : $\mathrm{F}(2,40)=5.14, p=0.010, \eta p 2=0.20$ RDIST $_{\mathrm{ML}}: \mathrm{F}(2,40)=20.65, p<0.001, \eta \mathrm{p} 2=0.51$; MVEL: $\mathrm{F}(1.37,27.34)=21.04, p<0.001, \eta \mathrm{p} 2=0.51 ; \mathrm{MVEL}_{\mathrm{AP}}: \mathrm{F}(1.30,26.07)=11.98, p=0.001$, $\eta \mathrm{p} 2=0.37 ;$ MVEL $_{\mathrm{ML}}: \mathrm{F}(2,40)=35.51, p<0.001, \eta \mathrm{p} 2=0.64 ; \operatorname{AREA}_{\mathrm{CC}}: \mathrm{F}(1.28,25.62)=$ $7.01, p=0.009, \eta p 2=0.26$; AREA $\left._{\mathrm{CE}}: \mathrm{F}(1.43,28.67)=13.14, p<0.001, \eta p 2=0.40\right)$ and the interaction of the target distance and direction $\left(\right.$ MDIST $_{\mathrm{ML}}: \mathrm{F}(5.01,100.20)=2.84, p=0.019$, $\eta \mathrm{p} 2=0.12 ; \operatorname{RDIST}_{\mathrm{ML}}: \mathrm{F}(4.99,99.84)=2.91, p=0.017, \eta p 2=0.13 ; \mathrm{MVEL}: \mathrm{F}(3.28,65.63)=3.33$, $p=0.021, \eta p 2=0.14$ MVEL $\left._{\mathrm{ML}}: \mathrm{F}(5.10,101.91)=3.29, p=0.008, \eta p 2=0.14\right)$ had significant effects on the balance control. The post-hoc tests on the target distance revealed that the postural sway was significantly increased as the target distance was further increased (Table 4). Although there were no significant effects of the direction, the interaction effects were found in the ML direction measures and the MVEL. In the post-hoc tests of simple effects (Table 5), there were no significant effects of the target distance on the measures in the $\mathrm{W}$ direction. In a comparison of the values in the directions at distance 1, there were significant effects on the MDIST $_{M L}$ and the RDIST ${ }_{M L}$ with decreasing postural sway from the left and right directions (E and $\mathrm{W}$ directions) to the forward directions (N, NE, and NW directions).

Table 4. Summary of COP outcomes and subjective assessments in the balance task.

\begin{tabular}{|c|c|c|c|c|c|c|c|c|c|}
\hline \multirow{2}{*}{ DV } & \multicolumn{3}{|c|}{ Goal Target Distance } & \multicolumn{5}{|c|}{ Goal Target Direction } & \multirow{2}{*}{$\begin{array}{c}\text { Interaction } \\
p \text {-Value }\end{array}$} \\
\hline & Distance 1 & Distance 2 & Distance 3 & $\mathrm{E}$ & $\mathbf{N}$ & NE & NW & $\mathbf{W}$ & \\
\hline MDIST & $0.21^{\mathrm{A}}(0.01)$ & $0.24^{\mathrm{B}}(0.02)$ & $0.26^{\mathrm{B}}(0.02)$ & $0.25(0.03)$ & $0.26(0.02)$ & $0.23(0.02)$ & $0.21(0.01)$ & $0.24(0.02)$ & 0.113 \\
\hline $\mathrm{MDIST}_{\mathrm{AP}}$ & $0.17^{\mathrm{A}}(0.01)$ & $0.20^{\mathrm{B}}(0.01)$ & $0.19^{\mathrm{B}}(0.01)$ & $0.20(0.02)$ & $0.20(0.02)$ & $0.19(0.02)$ & $0.16(0.01)$ & $0.18(0.01)$ & 0.482 \\
\hline $\mathrm{MDIST}_{\mathrm{ML}}$ & $0.09^{\mathrm{A}}(0.01)$ & $0.10^{\mathrm{A}}(0.01)$ & $0.14^{\mathrm{B}}(0.01)$ & $0.11(0.01)$ & $0.12(0.01)$ & $0.10(0.01)$ & $0.10(0.01)$ & $0.12(0.01)$ & 0.019 \\
\hline RDIST & $0.23^{\mathrm{A}}(0.02)$ & $0.27^{\mathrm{B}}(0.02)$ & $0.30^{\mathrm{B}}(0.02)$ & $0.28(0.03)$ & $0.29(0.02)$ & $0.27(0.02)$ & $0.24(0.02)$ & $0.26(0.02)$ & 0.103 \\
\hline $\mathrm{RDIST}_{\mathrm{AP}}$ & $0.20^{\mathrm{A}}(0.01)$ & $0.24^{\mathrm{B}}(0.02)$ & $0.24^{\mathrm{B}}(0.03)$ & $0.24(0.03)$ & $0.24(0.02)$ & $0.23(0.02)$ & $0.19(0.01)$ & $0.21(0.01)$ & 0.327 \\
\hline RDIST $_{M L}$ & $0.11^{\mathrm{A}}(0.01)$ & $0.13^{\mathrm{A}}(0.01)$ & $0.17^{\mathrm{B}}(0.01)$ & $0.13(0.01)$ & $0.14(0.01)$ & $0.13(0.01)$ & $0.13(0.01)$ & $0.14(0.01)$ & 0.017 \\
\hline MVEL & $0.82^{\mathrm{A}}(0.06)$ & $0.98^{\mathrm{B}}(0.07)$ & $1.22^{\mathrm{C}}(0.10)$ & $1.02(0.11)$ & $1.10(0.09)$ & $1.04(0.11)$ & $0.93(0.07)$ & $0.94(0.07)$ & 0.021 \\
\hline MVEL $_{\mathrm{AP}}$ & $0.62^{\mathrm{A}}(0.05)$ & $0.74^{\mathrm{B}}(0.06)$ & $0.88^{\mathrm{C}}(0.08)$ & $0.75(0.10)$ & $0.84(0.06)$ & $0.80(0.10)$ & $0.68(0.06)$ & $0.65(0.05)$ & 0.053 \\
\hline MVEL $_{\mathrm{ML}}$ & $0.42^{\mathrm{A}}(0.03)$ & $0.49^{\mathrm{B}}(0.04)$ & $0.65^{\mathrm{C}}(0.05)$ & $0.54(0.05)$ & $0.54(0.05)$ & $0.49(0.04)$ & $0.49(0.03)$ & $0.54(0.04)$ & 0.008 \\
\hline AREA $_{C C}$ & $0.51^{\mathrm{A}}(0.07)$ & $0.76^{\mathrm{B}}(0.12)$ & $0.98^{\mathrm{B}}(0.17)$ & $0.93(0.29)$ & $0.87(0.13)$ & $0.77(0.17)$ & $0.54(0.07)$ & $0.65(0.09)$ & 0.239 \\
\hline $\mathrm{AREA}_{\mathrm{CE}}$ & $0.42^{\mathrm{A}}(0.06)$ & $0.57^{\mathrm{B}}(0.08)$ & $0.80^{\mathrm{C}}(0.11)$ & $0.66(0.17)$ & $0.69(0.11)$ & $0.56(0.08)$ & $0.47(0.07)$ & $0.59(0.08)$ & 0.057 \\
\hline PP & $3.71^{\mathrm{A}}(0.13)$ & $3.68^{\mathrm{A}}(0.14)$ & $3.32^{\mathrm{B}}(0.16)$ & $3.52(0.17)$ & $3.44(0.17)$ & $3.65(0.16)$ & $3.73(0.14)$ & $3.51(0.18)$ & 0.053 \\
\hline ET & $3.71^{\mathrm{A}}(0.16)$ & $3.40^{\mathrm{B}}(0.12)$ & $2.80^{\mathrm{C}}(0.13)$ & $3.49(0.18)$ & $3.05(0.12)$ & $3.35(0.13)$ & $3.30(0.15)$ & $3.33(0.18)$ & 0.000 \\
\hline PS & $4.58^{\mathrm{A}}(0.09)$ & $4.13^{\mathrm{B}}(0.11)$ & $3.28^{\mathrm{C}}(0.13)$ & $4.29^{a}(0.12)$ & $3.44^{\mathrm{c}}(0.15)$ & $3.95^{\mathrm{b}}(0.14)$ & $4.05^{\mathrm{b}}(0.11)$ & $4.25^{\mathrm{ab}}(0.14)$ & 0.000 \\
\hline PC & $3.72^{\mathrm{A}}(0.12)$ & $3.38^{\mathrm{B}}(0.12)$ & $2.66^{\mathrm{C}}(0.13)$ & $3.43^{\mathrm{ab}}(0.14)$ & $2.83^{\mathrm{C}}(0.13)$ & $3.24^{\mathrm{ab}}(0.13)$ & $3.21^{\mathrm{b}}(0.14)$ & $3.57^{\mathrm{a}}(0.18)$ & 0.001 \\
\hline
\end{tabular}

Note: Values represent mean (standard error). Superscript denotes significant differences by different letters from indicated main effect condition $(p<0.05)$. Uppercase letters are used to indicate the significant difference by target distances 1,2 , and 3 . Lowercase letters are used to indicate the significant difference by target directions $\mathrm{E}, \mathrm{N}, \mathrm{NE}, \mathrm{NW}$, and $\mathrm{W}$. 
Table 5. Results of ANOVA for simple main effects in the weight-shifting tasks.

\begin{tabular}{|c|c|c|c|c|c|c|}
\hline \multirow{2}{*}{ DV } & \multirow{2}{*}{ Target Distance } & \multicolumn{5}{|c|}{ Target Direction } \\
\hline & & $\mathbf{E}$ & $\mathbf{N}$ & NE & NW & W \\
\hline \multirow{3}{*}{ MDIST $_{M L}$} & Distance 1 & $0.09^{\mathrm{ab}}(0.01)$ & $0.08^{\mathrm{Ab}}(0.01)$ & $0.08^{\mathrm{Ab}}(0.01)$ & $0.08^{\mathrm{Ab}}(0.01)$ & $0.12^{\mathrm{a}}(0.01)$ \\
\hline & Distance 2 & $0.11(0.01)$ & $0.09^{\mathrm{A}}(0.01)$ & $0.10^{\mathrm{A}}(0.01)$ & $0.09^{\mathrm{AB}}(0.01)$ & $0.12(0.02)$ \\
\hline & Distance 3 & $0.13(0.01)$ & $0.18^{\mathrm{B}}(0.03)$ & $0.13^{\mathrm{B}}(0.01)$ & $0.13^{\mathrm{B}}(0.02)$ & $0.12(0.01)$ \\
\hline \multirow{3}{*}{$\operatorname{RDIST}_{M L}$} & Distance 1 & $0.11^{\mathrm{Aab}}(0.01)$ & $0.09^{\mathrm{Ab}}(0.01)$ & $0.10^{\mathrm{Ab}}(0.01)$ & $0.10^{\mathrm{Ab}}(0.01)$ & $0.14^{\mathrm{a}}(0.02)$ \\
\hline & Distance 2 & $0.13^{\mathrm{AB}}(0.02)$ & $0.11^{\mathrm{A}}(0.01)$ & $0.12^{\mathrm{A}}(0.01)$ & $0.11^{\mathrm{AB}}(0.01)$ & $0.15(0.02)$ \\
\hline & Distance 3 & $0.16^{\mathrm{B}}(0.02)$ & $0.22^{\mathrm{B}}(0.03)$ & $0.15^{\mathrm{B}}(0.02)$ & $0.16^{\mathrm{B}}(0.02)$ & $0.15(0.01)$ \\
\hline \multirow{3}{*}{ MVEL } & Distance 1 & $0.85^{\mathrm{A}}(0.09)$ & $0.77^{\mathrm{A}}(0.06)$ & $0.79^{\mathrm{A}}(0.07)$ & $0.82^{\mathrm{A}}(0.09)$ & $0.88(0.07)$ \\
\hline & Distance 2 & $1.11^{\mathrm{B}}(0.14)$ & $1.00^{\mathrm{B}}(0.08)$ & $0.90^{\mathrm{B}}(0.07)$ & $0.91^{\mathrm{AB}}(0.07)$ & $0.96(0.10)$ \\
\hline & Distance 3 & $1.10^{\mathrm{B}}(0.14)$ & $1.54^{\mathrm{C}}(0.17)$ & $1.42^{\mathrm{B}}(0.26)$ & $1.06^{\mathrm{B}}(0.08)$ & $0.97(0.08)$ \\
\hline \multirow{3}{*}{ MVEL $_{M L}$} & Distance 1 & $0.43^{\mathrm{A}}(0.04)$ & $0.37^{\mathrm{A}}(0.04)$ & $0.38^{\mathrm{A}}(0.03)$ & $0.39^{\mathrm{A}}(0.03)$ & $0.51(0.06)$ \\
\hline & Distance 2 & $0.54^{\mathrm{AB}}(0.06)$ & $0.43^{\mathrm{A}}(0.04)$ & $0.46^{\mathrm{A}}(0.04)$ & $0.46^{\mathrm{A}}(0.04)$ & $0.53(0.05)$ \\
\hline & Distance 3 & $0.65^{\mathrm{B}}(0.07)$ & $0.81^{\mathrm{B}}(0.11)$ & $0.61^{\mathrm{B}}(0.06)$ & $0.61^{\mathrm{B}}(0.05)$ & $0.57(0.04)$ \\
\hline \multirow{3}{*}{ ET } & Distance 1 & $3.62(0.23)$ & $3.90^{\mathrm{A}}(0.17)$ & $3.86^{\mathrm{A}}(0.20)$ & $3.62^{\mathrm{A}}(0.21)$ & $3.57(0.25)$ \\
\hline & Distance 2 & $3.48(0.24)$ & $3.33^{\mathrm{B}}(0.16)$ & $3.52^{\mathrm{A}}(0.18)$ & $3.43^{\mathrm{AB}}(0.21)$ & $3.24(0.21)$ \\
\hline & Distance 3 & $3.38^{\mathrm{a}}(0.20)$ & $1.90^{\mathrm{Cc}}(0.15)$ & $2.67^{\mathrm{Bb}}(0.20)$ & $2.86^{\mathrm{Bb}}(0.22)$ & $3.19^{\mathrm{ab}}(0.22)$ \\
\hline \multirow{3}{*}{ PS } & Distance 1 & $4.86^{\mathrm{A}}(0.08)$ & $4.38^{\mathrm{A}}(0.19)$ & $4.48^{\mathrm{A}}(0.13)$ & $4.57^{\mathrm{A}}(0.13)$ & $4.62^{\mathrm{A}}(0.15)$ \\
\hline & Distance 2 & $4.24^{\mathrm{B}}(0.17)$ & $3.86^{\mathrm{B}}(0.20)$ & $4.05^{\mathrm{B}}(0.16)$ & $4.19^{\mathrm{A}}(0.15)$ & $4.33^{\mathrm{B}}(0.14)$ \\
\hline & Distance 3 & $3.76^{\mathrm{Ca}}(0.21)$ & $2.10^{\mathrm{Cb}}(0.15)$ & $3.33^{\mathrm{Ca}}(0.22)$ & $3.38^{\mathrm{Ba}}(0.19)$ & $3.81^{\mathrm{Ca}}(0.25)$ \\
\hline \multirow{3}{*}{ PC } & Distance 1 & $3.62(0.21)$ & $3.57^{\mathrm{A}}(0.21)$ & $3.71^{\mathrm{A}}(0.16)$ & $3.71^{\mathrm{A}}(0.18)$ & $4.00^{\mathrm{A}}(0.17)$ \\
\hline & Distance 2 & $3.57(0.19)$ & $3.19^{\mathrm{A}}(0.16)$ & $3.33^{\mathrm{A}}(0.20)$ & $3.19^{\mathrm{B}}(0.19)$ & $3.62^{\mathrm{B}}(0.23)$ \\
\hline & Distance 3 & $3.10^{\mathrm{a}}(0.19)$ & $1.71^{\mathrm{Bb}}(0.17)$ & $2.67^{\mathrm{Ba}}(0.21)$ & $2.71^{\mathrm{Ca}}(0.16)$ & $3.10^{\mathrm{Ca}}(0.24)$ \\
\hline
\end{tabular}

Note: Values represent mean (standard error). Superscript with uppercase letters denotes significant differences from the target distance effect condition $(p<0.05)$ within each target direction. Superscript with lowercase letters denotes significant differences from the target direction effect condition $(p<0.05)$ within each target distance.

\subsubsection{Subjective Measures}

The ANOVA results showed that the target distance (PP: $\mathrm{F}(2,40)=8.59, p<0.001$, $\eta \mathrm{p} 2=0.30 ; \mathrm{ET}: \mathrm{F}(2,40)=28.91, p<0.001, \eta \mathrm{p} 2=0.59 ; \mathrm{PS}: \mathrm{F}(1.31,26.23)=102.06, p<0.001$, $\eta \mathrm{p} 2=0.84 ; \mathrm{PC}: \mathrm{F}(1.67,33.34)=37.89, p<0.001, \eta \mathrm{p} 2=0.65)$, target direction $(\mathrm{PS}: \mathrm{F}(3.03$, $60.60)=10.41, p<0.001, \eta p 2=0.34 ; \mathrm{PC}: \mathrm{F}(4,80)=5.55, p=0.001, \eta \mathrm{p} 2=0.22)$, and interaction of the target distance and direction (ET: $\mathrm{F}(8,160)=5.53, p<0.001$, $\eta \mathrm{p} 2=0.22$; PS: $\mathrm{F}(5.79$, $115.84)=6.02, p<0.001, \eta p 2=0.23$; PC: $\mathrm{F}(8,160)=3.72, p=0.001, \eta p 2=0.16)$ had significant effects on the subjective evaluation of the balance control task. In the post-hoc tests, all the subjective ratings significantly decreased as the target distance increased (Table 5). The PP and ET were only affected by the target distance, but there was a significant interaction effect between the target distance and direction on the ET. Both the PS and PC were also significantly affected by the target direction and there were significant interaction effects of the target distance and direction on them. In a comparison of the values in the directions at each distance, the ET, PS, and PC showed significant differences only at distance 3 . The post-hoc tests on the simple effects revealed that the ET, PS, and PC decreased from the left and right directions ( $\mathrm{W}$ and $\mathrm{E}$ ) to the forward directions (NW, NE, and N).

\section{Discussion}

\subsection{Performance and Pattern of the Targeted Weight Shifting}

4.1.1. Effects of Target Distance on the Weight-Shifting Performance

In the weight-shifting task, the target distance was found to affect the time, fluency, and accuracy of the COP movements, which is consistent with the findings from previous studies $[30,37,38]$. When the target distance was increased, the MT increased, the movement trajectory fluctuated more, and a larger variation with more time was required around the goal target. In other words, a farther target distance increases the task difficulty and affects the movement strategy. In this circumstance, the postural control requires more resources and takes longer to execute with larger amplitudes. This relationship 
was also reported in other studies regarding voluntary movements of other limbs under goal-directed movements with speed and accuracy trade-off.

However, as shown in the post-hoc tests, the DC was not significantly affected by the target distance. This indicated that the farther target distance of the COP movements not only induced more fluctuations toward the off-axis but also increased the movement length toward the on-axis, and their ability to control the COP movement direction was not affected by the distance. This indicates the ability to precisely aim a target was not affected.

In terms of accuracy, de Vries et al. [30] showed that increasing the target distance decreases the accuracy of the targeted COP movement. In this study, the TESSS and DT were significantly increased as the target distance increased but the ME and the TA were not significantly affected. These indicated that the SSM lasted longer with an increase in the target distance but the controls of the movement around the target were not significantly different by the given target distance. From this perspective, the precision of weight-shifting control at the target area was not affected by the target distance in this experiment.

\subsubsection{Effects of Target Direction on the Weight-Shifting Performance}

The results showed that the COP movement was also affected by the target directions, and the movement strategies could be classified into three groups as follows: (1) N direction, (2) E and W directions, and (3) NE and NW directions. In terms of MT, the total MT was not significantly affected by the target direction. However, the $\mathrm{MT}_{\mathrm{PMS}}$ values in the $\mathrm{E}$ and $\mathrm{W}$ directions were significantly larger than those in the other directions. Regarding fluency measures, the COP movement was the most fluent when the target was located in the $\mathrm{N}$ direction, followed by the $\mathrm{E}$ and $\mathrm{W}$ directions and the NE and NW directions. However, the ability to control the COP movement direction was not significantly different between the cases when the target was located in the $\mathrm{N}$ direction and when it was in the $\mathrm{E}$ and $\mathrm{W}$ directions. In terms of accuracy, the participants showed the best performance mostly when the target was located in the $\mathrm{N}$ direction while the performances in the remaining four directions were not significantly different from each other.

In summary, the COP movement in the $\mathrm{N}$ direction was relatively slow before it reached a target but showed better accuracy of aiming, and its movement pattern was closest to the ideal path along the on-axis. The COP movements in the $\mathrm{E}$ and $\mathrm{W}$ directions were faster than those in the other directions, but they fluctuated more than the movement in the $\mathrm{N}$ direction and were less accurate. The COP movements in the NE and NW directions showed the worst performance in terms of the time, fluency, and accuracy.

The different patterns of the COP movement by the target direction implied that postural control strategies can be implemented differently according to the weight-shifting directions. In previous studies, an inverted pendulum model had been extensively investigated to explain postural control of the human body [36,39-41]. In the model, an ankle strategy is applied in the AP direction while a hip strategy dominates in the ML direction during standing still [9]. The characteristics of each strategy are obviously different in terms of precise control and force application $[42,43]$.

In this regard, the accuracy in the $\mathrm{N}$ direction was higher than those in the other directions due to the ankle strategy used to control posture. The diagonal weight shifts (i.e., in the NE and NW directions) can be interpreted as a combination of both the ankle and hip strategies but it seems that it is mostly affected by the hip strategy. The COP movement pattern of the diagonal weight shifts was similar to that of the lateral weight shifts (i.e., in the $\mathrm{E}$ and $\mathrm{W}$ directions) rather than that of the anterior weight shift (i.e., in the $\mathrm{N}$ direction) in terms of movement fluency and accuracy.

\subsubsection{Interaction Effects of Target Distance and Direction on the Weight-Shifting Performance}

Apart from the individual effects of distance and direction, there were interaction effects on the time and fluency of the COP movements. The $\mathrm{MT}_{\mathrm{PMS}}$ showed significant differences between the target distances in each target direction but there were patterns of non-significant differences between the values in the distances. The different patterns were 
classified into three groups: (1) N direction, (2) E and NE directions, and (3) W and NW directions. These different patterns by direction may be a result of the subject's footedness as most of their preferred foot was the right foot. As the preferred foot is commonly used to manipulate an object or mobilize an action while the non-preferred foot is used to support the action for postural stability $[44,45]$, the $\mathrm{MT}_{\mathrm{PMS}}$ can vary depending on which foot is used to mobilize or stabilize the whole-body movement. The foot on the side of the target location performs the stabilizing role of the movement while the opposite foot mobilizes the movement. When the target was located on the left side of a subject, the right foot, which was the mobilizing foot, was effective in moving the whole body quickly without a significant increase in the time, although the target distance increased from distance 2 to distance 3 . However, when the target was located on the right side, the $\mathrm{MT}_{\mathrm{PMS}}$ significantly increased when the target distance increased as the former.

In terms of fluency, the interaction effects revealed that the COP movement strategy can be varied by the target direction but there are also different ranges applied according to the direction. When comparing the $\mathrm{d}_{\mathrm{NMP}}$ of the target directions in each target distance, the differences between the values in the directions increased as the target distance increased. The lateral and diagonal COP movements did not show a significant difference in terms of the $\mathrm{d}_{\mathrm{NMP}}$ when the target was located at distance 1, but they did when the target was located farther at distance 3 . With respect to the MD, there was also a similar pattern in that a significant difference between the lateral movement and the anterior movement was not found within target distance 2, but it was found at target distance 3 . These results imply that the difference in the COP movement fluency between the target directions becomes greater when the target distance increases. It may imply the boundary that the weight-shifting performance is affected and may also be considered in the perspective of the functional stability region [27].

\subsubsection{Subjective Measures of the Weight Shifting}

There were significant interaction effects of the target distance and the target direction on the subjective measures. When comparing the effects of the target direction in each target distance, three assessments, namely the PP, ET, and PS, showed significant differences only at distance 3. In other words, there were no effects of the target direction on the PP, ET, and PS within the range of distance 2. However, at distance 3, the three assessments showed a similar pattern in that subjects felt better in terms of PP, ET, and PS when shifting their weights laterally. This pattern was also found in all target distances of PC. In short, there are effects of the target directions on the subjective assessments, and humans perceive that lateral whole-body movements are better, easier, more stable, and more comfortable than the other directional movements when shifting their weights rapidly and farther.

\subsection{Performance of the Balance Control}

\subsubsection{Effects of Target Distance and Direction on the Balance Control}

Maintaining balance with control of the COP at a target within the BOS was found to be most affected by the target distance. Previous studies showed similar results that the leaning posture increased postural sway and instability [31,46,47]. In this study, the postural stability was deteriorated significantly with an increase in the COP target distance from the neutral position. When the body is leaning, the moments at the ankle joints are higher than when the body is at the neutral standing position. This also increases muscle activation to maintain the leaning posture and causes more force exertion, which leads to higher postural instability.

However, the effect of leaning posture on the postural sway can be varied according to the leaning direction. There were four distance-based COP measures that have interaction effects with the target distance and direction, and three of them were the measures in the ML direction. There was also no effect of the target distance on the four measures in the $\mathrm{W}$ direction. These results imply that the target distance considerably affects the postural sway in the AP direction, and there may also be some effects of footedness on the postural 
sway in the ML direction as most of the participants were right-footed. In this study, a comparison of the values of postural stability by the target direction showed no significant differences, but this may be due to the short periods of measurement for each trial. The effects of the leaning direction with longer durations need to be further studied in relation to the directional control of the SPMD.

\subsubsection{Subjective Assessments of the Balance Control}

In the subjective evaluation of the balance task, the target distance showed significant effects on the four assessments. This indicates that participants can discriminate levels of the task difficulty and postural stability of the task caused by the target distance. From the post-hoc analysis of the simple main effects of the target directions, there were significant differences only in target distance 3. However, as previously mentioned, the postural sway was not affected by the target direction except for the sway along the ML direction at distance 1. This might imply that adults perceive the effects of the leaning direction differently when their leaning position exceeds some area of boundary. Further, the objective and subjective measures can differ in terms of balance control. This discrepancy needs to be further studied when considering the perception of stability in such cases of balance training.

\subsection{Application to the SPMD}

In this study, the contexts of riding the SPMD to move at a standstill and to maintain a constant speed were considered by the balance control using the whole-body movements. It was investigated with the body movement direction and distance. The experimental factors of the direction and distance were controlled using the COP and examined for both the weight-shifting ability and the postural steadiness in order to consider the riding contexts.

Although the COP movements on the flat surface may not be directly applied to the COP movements on the SPMD due to its various design characteristics of the SPMD, the weight-shifting ability and the maintaining postural equilibrium of a rider are expected to yield similar patterns based on the leaning direction and distance of a rider on the SPMD. The measures derived in both weight-shifting and balance task analysis can be also utilized to assess a rider's performance on the SPMD while the ranges of the target distance and direction have to be modified further based on riding speed and control types of the SPMD. The rider's motion of leaning on an SPMD is directly related to accelerating the speed of the SPMD. The target distance of the COP was used for controlling conditions of the experiment in this study. It can be also applied that achieving a certain level of riding speed is controlled to examine the COP movements for analyzing the performance of a

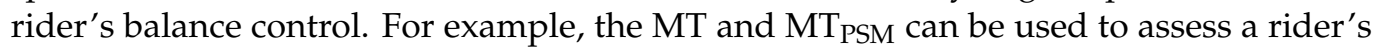
weight-shifting performance on how fast and accurately the rider controls the Segway mini within a moving forward direction while achieving certain levels of speed.

As aforementioned, design characteristics of the SPMD can differ a lot based on each type of the SPMD. The type can be classified by design factors such as the number of wheels, direction control methods, riding postures, control sensitivity and etc. For example, Segway drift is a self-balancing electric skate that is two separate skates with one small wheel for each and limited in performances such as speed and climbing. Since the combination of the design factors can increase the difficulty of an experiment dramatically, those factors are difficult to be incorporated into the research design all in one in an experimental environment. Furthermore, riding the SPMD in the experiment demands recruiting participants of fully skilled riders and ensuring safety concerns. In this point of view, the experiment requires simplified conditions to generalize the concept of the balance control in the context of riding the SPMD as a preliminary study before developing the study in line with each type of the SPMD.

There are tremendously a lot of studies in the field of human balance research. Many of those used the COP as an objective measure for the evaluation of balance. Although they are quite relevant, this study deeply and comprehensively studied the factors of target 
direction and distance using both objective and subjective measures. Further, the objective measures in the weight-shifting task were derived from two specific submovements and reorganized into three types to describe the COP movement of a goal-directed wholebody movement. These measures can also be utilized in other similar studies of postural movement. The method of measuring the postural equilibrium with specific postures controlled by the COP was conducted only for $3 \mathrm{~s}$ of recording the COP in the balance task. This is because participants were given enough time of practice and they located their COP at target locations with their own face before the recording started. In addition, the realtime COP feedback was used as a means of performing tasks during both weight-shifting and balance tasks but also as visual feedback for participants constantly receiving their instant status and interacting with it for their balance control. It works as if SPMD riders receive feedbacks while riding such as vision, vibration, and others. At the same time, they control their balance interacting with the device just as participants performed the tasks with the COP feedback.

There are some limitations of this study. First, only a fixed target width was adopted, which can affect the accuracy of the performance in the weight-shifting task. Changing the target size can refine the COP movement strategy by the target direction. Second, external perturbations, such as acceleration force and vibration of the SPMD, which can occur during riding the vehicle, were not considered as well. Furthermore, the balance control may vary according to the rider's characteristics, e.g., age and injury, and design parameters such as foot position, height of control bar, and number of wheels. Lastly, the experiments were conducted with a relatively small sample size of young adults. Although the repeated-measures ANOVA is robust to the violation of the assumptions especially when the design is balanced [48,49], it is better recommended to be tested with a larger sample size if possible. The majority of the SPMD riders in current markets are expected to be teenagers and young adults. However, the SPMD has to be considered as designed for a broader age range of the rider since it is also considered as one type of future mobilities. In future studies, these limitations will be considered when designing an experimental setup.

\section{Conclusions}

This study aimed to understand weight-shifting ability and balance control, which are important aspects when riding an SPMD. The weight-shifting ability was investigated using various target distances and directions on a force plate using the COP under goaldirected movements and accuracy constraints. The balance control was also evaluated using the target distances and directions within the BOS using the COP. The experimental results showed that the performances of weight-shifting ability and balance control were affected by the COP target distance and direction using whole-body movements. In the weight-shifting task during upright standing, the farther targeted whole-body movement significantly increased the MT and decreased the movement fluency and accuracy. Moreover, the MT, fluency, and accuracy showed significant differences and distinguishing patterns by the movement direction. In the balance control with postural equilibrium during upright standing, the target distance significantly affected the postural stability, and there were also interaction effects with the target direction on the postural sway along the ML direction. In both tasks, the results indicate that both the target distance and the target direction affect the performance of weight-shifting ability and balance control in terms of objective and subjective measures. As a preliminary study, this study is expected to be utilized in further studies to include design factors of different SPMDs.

Author Contributions: Conceptualization, D.P. and Y.L.; methodology, D.P. and Y.L.; software, D.P.; validation, D.P. and Y.L.; formal analysis, D.P. and Y.L.; investigation, D.P.; resources, Y.L. and M.Y.; data curation, D.P.; writing-original draft preparation, D.P.; writing—review and editing, Y.L. and M.Y.; visualization, D.P.; supervision, Y.L. and M.Y.; project administration, Y.L.; funding acquisition, Y.L. All authors have read and agreed to the published version of the manuscript.

Funding: This work was supported by a Research Grant of Pukyong National University (2020). 
Informed Consent Statement: Informed consent was obtained from all subjects involved in the study.

Acknowledgments: The authors thank the administrative support from the Industrial Systems Innovative Research Institute of Pukyong National University.

Conflicts of Interest: The authors declare no conflict of interest.

\section{Appendix A}

Questions used in subjective measures for the weight-shifting task and the balance task are described with candidate answers.

Table A1. Questions for Weight-shifting task.

\begin{tabular}{|c|c|c|}
\hline & Questions & Item Scale \\
\hline 1. & $\begin{array}{l}\text { Perceived performance (PP): I completed the task very well } \\
\text { as fast and accurately as possible. }\end{array}$ & \\
\hline 2. & Ease of task (ET): This task was easy to be completed. & $\begin{array}{l}\text { 1. Strongly disagree } \\
\text { 2. Disagree }\end{array}$ \\
\hline 3. & $\begin{array}{l}\text { Perceived stability (PS): I did not feel afraid of falling and } \\
\text { felt stable while I was performing the task. }\end{array}$ & $\begin{array}{ll}\text { 3. } & \text { Neutral } \\
\text { 4. } & \text { Agree } \\
\text { 5. } & \text { Strongly agree }\end{array}$ \\
\hline 4. & $\begin{array}{l}\text { Physical comfort (PC): I felt physically comfortable while } \\
\text { performing the task. }\end{array}$ & \\
\hline
\end{tabular}

Table A2. Questions for Balance task.

\begin{tabular}{|c|c|c|}
\hline & Questions & Item Scale \\
\hline 1. & $\begin{array}{l}\text { Perceived performance (PP): I completed the task very well } \\
\text { as balancing steady as possible. }\end{array}$ & \\
\hline 2. & Ease of task (ET): This task was easy to be completed. & $\begin{array}{l}\text { 1. Strongly disagree } \\
\text { 2. Disagree }\end{array}$ \\
\hline 3. & $\begin{array}{l}\text { Perceived stability (PS): I did not feel afraid of falling and } \\
\text { felt stable while I was performing the task. }\end{array}$ & $\begin{array}{ll}\text { 3. } & \text { Neutral } \\
\text { 4. } & \text { Agree } \\
\text { 5. } & \text { Strongly agree }\end{array}$ \\
\hline 4. & $\begin{array}{l}\text { Physical comfort (PC): I felt physically comfortable while } \\
\text { performing the task. }\end{array}$ & \\
\hline
\end{tabular}

\section{References}

1. Ulrich, K.T. Estimating the technology frontier for personal electric vehicles. Transp. Res. Part C Emerg. Technol. 2005, 13, 448-462. [CrossRef]

2. Liu, R.; Parthasarathy, R. Urban Street: Is There Room for Segway (Trademark) Human Transporter (HT)? In Proceedings of the 2nd Urban Street Symposium: Uptown, Downtown, or Small Town: Designing Urban Streets That Work, Anaheim, CA, USA, 28-30 July 2003.

3. Shaheen, S.A.; Finson, R. Bridging the last mile: A study of the behavioral, institutional, and economic potential of the segway human transporter. Transp. Res. Board 2003, 10, 108-113.

4. Dias, C.; Nishiuchi, H.; Hyoudo, S.; Todoroki, T. Simulating interactions between pedestrians, Segway riders and cyclists in shared spaces using social force model. Transp. Res. Procedia 2018, 34, 91-98. [CrossRef]

5. Dowling, R.; Irwin, J.D.; Faulks, I.J.; Howitt, R. Use of personal mobility devices for first-and-last mile travel: The Macquarie-Ryde trial. In Proceedings of the 2015 Australasian Road Safety Conference, Gold Coast, Australia, 14-16 October 2015.

6. Hasegawa, Y.; Dias, C.; Iryo-Asano, M.; Nishiuchi, H. Modeling pedestrians' subjective danger perception toward personal mobility vehicles. Transp. Res. Part F Traffic Psychol. Behav. 2018, 56, 256-267. [CrossRef] 
7. Siracuse, B.L.; Ippolito, J.A.; Gibson, P.D.; Beebe, K.S. Hoverboards: A new cause of pediatric morbidity. Injury 2017, 48, 1110-1114. [CrossRef]

8. Pollock, A.S.; Durward, B.R.; Rowe, P.J.; Paul, J.P. What is balance? Clin. Rehabil. 2000, 14, 402-406. [CrossRef]

9. Winter, D.A. Human balance and posture control during standing and walking. Gait Posture 1995, 3, 193-214. [CrossRef]

10. Holbein, M.A.; Chaffin, D.B. Stability limits in extreme postures: Effects of load positioning, foot placement, and strength. Hum. Factors 1997, 39, 456-468. [CrossRef]

11. Horak, F.B. Clinical assessment of balance disorders. Gait Posture 1997, 6, 76-84. [CrossRef]

12. Shumway-Cook, A.; Woollacott, M.H. Theories of motor control. In Motor Control: Theory and Practical Applications; Williams \& Wilkins: Baltimore, MD, USA, 1995; Available online: https://lib.ugent.be/catalog/rug01:000390745 (accessed on 8 March 2021).

13. Lafond, D.; Duarte, M.; Prince, F. Comparison of three methods to estimate the center of mass during balance assessment. J. Biomech. 2004, 37, 1421-1426. [CrossRef]

14. Winter, D.A.; Patla, A.E.; Frank, J.S. Assessment of balance control in humans. Med. Prog. Technol. 1990, 16, 31-51. [PubMed]

15. Palmieri, R.M.; Ingersoll, C.D.; Stone, M.B.; Krause, B.A. Center-of-pressure parameters used in the assessment of postural control. J. Sport Rehabil. 2002, 11, 51-66. [CrossRef]

16. Riemann, B.L.; Guskiewicz, K.M.; Shields, E.W. Relationship between clinical and forceplate measures of postural stability. J. Sport Rehabil. 1999, 8, 71-82. [CrossRef]

17. DiDomenico, A.; Nussbaum, M.A. Interactive effects of mental and postural demands on subjective assessment of mental workload and postural stability. Saf. Sci. 2005, 43, 485-495. [CrossRef]

18. Hernandez, M.E.; Ashton-Miller, J.A.; Alexander, N.B. Age-related changes in speed and accuracy during rapid targeted center of pressure movements near the posterior limit of the base of support. Clin. Biomech. 2012, 27, 910-916. [CrossRef]

19. Hernandez, M.E.; Ashton-Miller, J.A.; Alexander, N.B. The effect of age, movement direction, and target size on the maximum speed of targeted COP movements in healthy women. Hum. Mov. Sci. 2012, 31, 1213-1223. [CrossRef]

20. Kasahara, S.; Saito, H.; Anjiki, T.; Osanai, H. The effect of aging on vertical postural control during the forward and backward shift of the center of pressure. Gait Posture 2015, 42, 448-454. [CrossRef]

21. Tucker, M.G.; Kavanagh, J.J.; Barrett, R.S.; Morrison, S. Age-related differences in postural reaction time and coordination during voluntary sway movements. Hum. Mov. Sci. 2008, 27, 728-737. [CrossRef]

22. Zultowski, I.; Aruin, A. Carrying loads and postural sway in standing: The effect of load placement and magnitude. Work 2008, 30, 359-368.

23. Jebelli, H.; Ahn, C.R.; Stentz, T.L. Fall risk analysis of construction workers using inertial measurement units: Validating the usefulness of the postural stability metrics in construction. Saf. Sci. 2016, 84, 161-170. [CrossRef]

24. Pan, C.S.; Chiou, S.; Kau, T.-Y.; Bhattacharya, A.; Ammons, D. Effects of foot placement on postural stability of construction workers on stilts. Appl. Ergon. 2009, 40, 781-789. [CrossRef]

25. Simeonov, P.I.; Hsiao, H.; Dotson, B.W.; Ammons, D.E. Control and perception of balance at elevated and sloped surfaces. Hum. Factors 2003, 45, 136-147. [CrossRef]

26. Soangra, R.; Bhatt, H.; Rashedi, E. Effects of load carriage and surface inclination on linear and non-linear postural variability. Saf. Sci. 2018, 110, 427-437. [CrossRef]

27. Holbein-Jenny, M.A.; McDermott, K.; Shaw, C.; Demchak, J. Validity of functional stability limits as a measure of balance in adults aged 23-73 years. Ergonomics 2007, 50, 631-646. [CrossRef]

28. Juras, G.; Słomka, K.; Fredyk, A.; Sobota, G.; Bacik, B. Evaluation of the limits of stability (LOS) balance test. J. Hum. Kinet. 2008, 19, 39-52. [CrossRef]

29. Spreitzer, L.; Perkins, J.; Ustinova, K.I. Challenging stability limits in old and young individuals with a functional reaching task. Am. J. Phys. Med. Rehabil. 2013, 92, 36-44. [CrossRef]

30. de Vries, E.A.; Caljouw, S.R.; Coppens, M.J.M.; Postema, K.; Verkerke, G.J.; Lamoth, C.J.C. Differences between young and older adults in the control of weight shifting within the surface of support. PLOS ONE 2014, 9, e98494.

31. Duarte, M.; Zatsiorsky, V.M. Effects of body lean and visual information on the equilibrium maintenance during stance. Exp. Brain Res. 2002, 146, 60-69. [CrossRef]

32. Prado, J.M.; Dinato, M.C.M.; Duarte, M. Age-related difference on weight transfer during unconstrained standing. Gait Posture 2011, 33, 93-97. [CrossRef]

33. Jongman, V.; Lamoth, C.J.C.; van Keeken, H.; Caljouw, S.R. Postural Control of Elderly: Moving to Predictable and Unpredictable Targets. Stud. Health Technol. Inform. 2012, 181, 93-97. [CrossRef]

34. Prieto, T.E.; Myklebust, J.B.; Hoffmann, R.G.; Lovett, E.G.; Myklebust, B.M. Measures of postural steadiness: Differences between healthy young and elderly adults. IEEE Trans. Biomed. Eng. 1996, 43, 956-966. [CrossRef]

35. Clark, S.; Rose, D.J.; Fujimoto, K. Generalizability of the limits of stability test in the evaluation of dynamic balance among older adults. Arch. Phys. Med. Rehabil. 1997, 78, 1078-1084. [CrossRef]

36. Kennedy, M.W.; Bretl, T.; Schmiedeler, J.P. Interpreting lateral dynamic weight shifts using a simple inverted pendulum model. Gait Posture 2014, 40, 134-139. [CrossRef]

37. Danion, F.; Duarte, M.; Grosjean, M. Fitts' law in human standing: The effect of scaling. Neurosci. Lett. 1999, 277, 131-133. [CrossRef]

38. Duarte, M.; Freitas, S.M.S.F. Speed-accuracy trade-off in voluntary postural movements. Motor Control 2005, 9, 180-196. [CrossRef] 
39. Karlsson, A.; Lanshammar, H. Analysis of postural sway strategies using an inverted pendulum model and force plate data. Gait Posture 1997, 5, 198-203. [CrossRef]

40. Loram, I.D.; Lakie, M. Human balancing of an inverted pendulum: Position control by small, ballistic-like, throw and catch movements. J. Physiol. 2002, 540, 1111-1124. [CrossRef]

41. Peterka, R.J. Postural control model interpretation of stabilogram diffusion analysis. Biol. Cybern. 2000, 82, 335-343. [CrossRef]

42. Amin, D.J.; Herrington, L.C. The relationship between ankle joint physiological characteristics and balance control during unilateral stance. Gait Posture 2014, 39, 718-722. [CrossRef]

43. Runge, C.F.; Shupert, C.L.; Horak, F.B.; Zajac, F.E. Ankle and hip postural strategies defined by joint torques. Gait Posture 1999, 10, 161-170. [CrossRef]

44. Peters, M. Footedness: Asymmetries in foot preference and skill and neuropsychological assessment of foot movement. Psychol. Bull. 1988, 103, 179. [CrossRef] [PubMed]

45. Sadeghi, H.; Allard, P.; Prince, F.; Labelle, H. Symmetry and limb dominance in able-bodied gait: A review. Gait Posture 2000, 12, 34-45. [CrossRef]

46. Blaszczyk, J.W.; Hansen, P.D.; Lowe, D.L. Postural sway and perception of the upright stance stability borders. Perception 1993, 22, 1333-1341. [CrossRef] [PubMed]

47. Riley, M.A.; Mitra, S.; Stoffregen, T.A.; Turvey, M.T. Influences of body lean and vision on unperturbed postural sway. Motor Control 1997, 1, 229-246. [CrossRef]

48. Sullivan, L.M.; Weinberg, J.; Keaney, J.F., Jr. Common statistical pitfalls in basic science research. J. Am. Heart Assoc. 2016, 5, e004142. [CrossRef]

49. Keselman, H.J.; Algina, J.; Kowalchuk, R.K. The analysis of repeated measures designs: A review. Br. J. Math. Stat. Psychol. 2001, 54, 1-20. [CrossRef] 